\title{
Risk Factors of Gestational Diabetes Mellitus in a Reference Maternal Health Care Centre in Southern Benin
}

\author{
Ogoudjobi OM ${ }^{1, *}$, Sossa Jérôme $C^{2}$, Lokossou MSHS ${ }^{1}$, Tshabu-Aguemon $C^{1}$, Kérékou ${ }^{1}$, \\ Tandjiékpon $\mathrm{E}^{1}$, Denakpo $\mathrm{JL}^{1}$, Perrin $\mathrm{R}-\mathrm{X}^{1}$ \\ ${ }^{1}$ Faculty of Health Sciences, University of Abomey-Calavi, Benin \\ ${ }^{2}$ Department of Health Promotion, Regional Institute of Public Health (IRSP), University of Abomey-Calavi, Benin
}

Copyright $\bigcirc 2017$ by authors, all rights reserved. Authors agree that this article remains permanently open access under the terms of the Creative Commons Attribution License 4.0 International License

\begin{abstract}
Gestational diabetes mellitus is the most commonly observed endocrine disorder during pregnancy. It results in severe fetal and maternal complications that can increase the fetal morbidity and mortality and the risk for overt diabetes in women. Identification of pregnant women at high risk for gestational diabetes mellitus is therefore needed for early detection in order to reduce its consequences for the mother, the fetus and the newborn. The objective of the study was to identify risk factors for gestational diabetes in a reference maternal health care centre in southern Benin. This was a case-control study carried out from 1st February 2015 to 31st July 2017 in reference maternal health care centre at the University Hospital of Porto-Novo. All pregnant women with a gestational age of 24 to 28 weeks of amenorrhea, who utilized antenatal care service of University Hospital of Porto-Novo, were screened for gestational diabetes mellitus. The chi-square test was used to identify risk factors for gestational diabetes mellitus. The statistical significance was fixed at $p<0.05$. Of the 967 pregnant women participated in the study, 73 cases of gestational diabetes mellitus, were detected (7.5\%). Risk factors of gestational diabetes identified were: maternal age $\geq 35$ years [OR 7.82 CI 95\% (4.75-12.89)], body mass index $\geq 25 \mathrm{~kg} / \mathrm{m}^{2}$ [OR 9.56 CI 95\% (5.17-17.70)], family history of diabetes at $1 \mathrm{st}$ degree [OR 2.78 CI 95\% (1.53-5.06)], a history of fetal macrosomia [OR 7.25 CI 95\% (3.11-16.92)], a history of stillbirth [OR 2.98 CI 95\% (1.78-5.00)], an antecedent of more than two spontaneous miscarriages [OR 1.93 CI 95\% (1.19-3.12)] and the personal history of hypertension [OR 3.91 CI 95\% (1.52-10.07)]. This study confirmed the influence of maternal age and some medical and obstetric histories as risk factors of gestational diabetes mellitus. These pregnant women at high risk of gestational diabetes mellitus should benefit from early detection.
\end{abstract}

Keywords Gestational Diabetes Mellitus, Risk Factors, WHO Test

\section{Introduction}

Gestational diabetes mellitus (GDM) is defined as any level of glucose intolerance with onset or first recognition during pregnancy in a woman with no evidence of diabetes or dysglycemia in the past time [1]. GDM is considered as the most commonly endocrine disorder observed during pregnancy, making it a high-risk pregnancy with both maternal, fetal and neonatal complications [2-5]. It results in severe fetal and maternal complications that can increase the fetal mortality and morbidity [6] and the risk for overt diabetes in women $[7,8]$. The prevalence of GDM is increasing worldwide. Yearly 21 million cases of the world are reported. GDM is more common in developing countries [9] due to decreasing levels of physical activity, changes in dietary patterns and increasing.

Therefore, identifying GDM risk factors for early detection is the key that may inform preventives measures to be taken timely to ensure satisfactory outcome of pregnancy [6]. The objective of the study was to identify risk factors for GDM in a reference maternal health care centre in southern Benin.

\section{Materials and Methods}

The case-control study was carried out at the maternal health care unit of the University Hospital of Porto-Novo, one of the largest reference hospitals in southern Benin. The study was conducted over a period of thirty (30) months from February 1rst, 2015 to July 31th, 2017. Screening test for GDM was performed for pregnant women between 24 and 28 weeks of amenorrhea. Pregnant women with evidence of diabetes or dysglycemia before or at the beginning of their pregnancy were excluded from the study. Informed consent or parental consent for pregnant women under 18 years of age was obtained prior to data collection. An appropriate 
blood collection room was prepared in the maternal health care service. Biochemical analyses of drawn blood samples were performed at the hospital laboratory. Blood glucose was measured by the glucose oxidase method [10] in the plasma of fasting subjects.

The screening was done according to the World Health Organization (WHO) test. Participants were asked to undergo for Oral Glucose Tolerance Test. All antenatal care attendees were given $75 \mathrm{gm}$ of glucose per $100 \mathrm{ml}$ of distilled water. The blood samples were collected after two hours' time for serum glucose levels. The serum glucose value exceeding $1.40 \mathrm{~g} / \mathrm{l}$ was declared as a case of GDM [11]. Thus, "Cases" were represented by pregnant women with blood glucose levels $\geq 1.40 \mathrm{~g} / 1$ and "Controls" refers to pregnant women with blood glucose levels $<1.40 \mathrm{~g} / \mathrm{l}$. The independent variables studied were: maternal age, socio-demographic profile, body mass index prior to pregnancy, medical and obstetric history. Data on independent variables were collected by documentary review. The dependent variable was the GDM. For the comparison of the results, we used the chi-square test and the difference was assumed to be statistically significant for a p less than 0.05 .

\subsection{Statistical Analysis}

Statistical analysis was done by using SPSS software application version 16. Proportions were calculated. Odds ratio were calculated with $95 \%$ confidence interval to identify risk factors of GDM. Statistical significance level was set at $\mathrm{p}<0.05$.

\subsection{Ethical Considerations}

The objectives of the study were explained to participants. Voluntary informed oral consent was obtained from each participating woman before starting blood collection. This consent claims that participants were not at risk by refusing to participate in the survey or stopping their collaboration during the study and would not have their maternity care impacted in any way prior to commencing the blood collection. The confidentiality of the data and the anonymity of the pregnant were respected.

\section{Results}

Among 967 pregnant women screened, 73 (7.5\%) cases of GDM were identified. The remaining 894 pregnant women were considered as "Controls".

\subsection{Characteristics of the Sample}

\subsubsection{Age of the Participants}

The mean age of the study population was $28.47 \pm 5.71$ years $(33 \pm 4.19$ years in case group vs $28 \pm 5.66$ years in control group) and ranged from 16 to 44 years. Prevalence of GDM increased significantly from 35 years of age $(\mathrm{p}=$ 0.0039) (Figure 1).

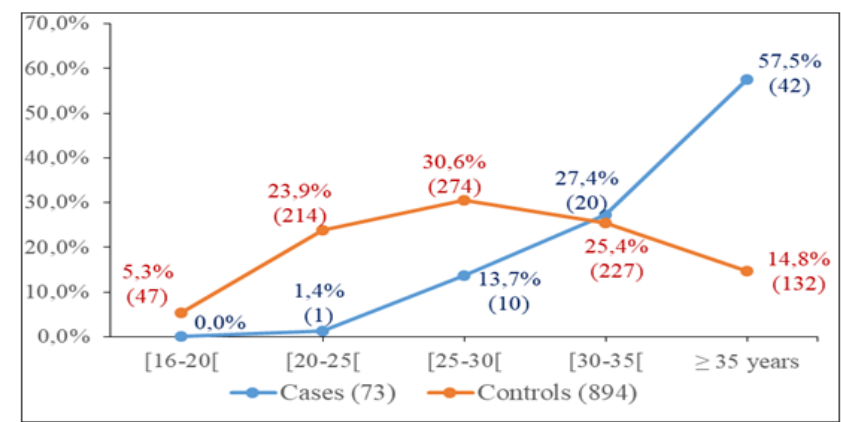

Figure 1. Age of women « Case » and « Controls » at university hospital of Porto-Novo, Benin, 2015-2017

\subsubsection{Occupation, Education and Marital Status of Pregnant} Women

Occupation, education and marital status of pregnant women were not associated with GDM (Table 1).

\subsubsection{Obstetric History of Pregnant Women}

Stillbirths, fetal macrosomia and more than two spontaneous miscarriages conditions were statistically more prevalent in pregnant with GDM (Table 2).

\subsubsection{Pregnant Women's Family and Individual Medical Histories}

GDM was statistically associated with an individual history of high blood pressure, body mass index, and family history of first-degree diabetes (Table 3).

\subsubsection{Risk Factors of Gestational Diabetes Mellitus}

Risk factors for gestational diabetes mellitus identified were: maternal age $\geq 35$ years, body mass index $\geq 25 \mathrm{~kg} / \mathrm{m}^{2}$, family history of first degree diabetes, history of fetal macrosomia, stillbirth, more than two spontaneous miscarriages, and personal history of high blood pressure (Table 4). 
Table 1. Occupation, education and marital status of "Case of GDM" and "Control" at university hospital of Porto-Novo, Benin, 2015-2017

\begin{tabular}{|c|c|c|c|c|}
\hline Variables & Total n (\%) & GDM Cases n (\%) & Controls n (\%) & $\mathbf{p}$ \\
\hline Occupation & & & & 0.2894 \\
\hline Businesswoman / Saleswoman & $383(39.6)$ & $26(35.6)$ & $357(40.0)$ & \\
\hline Housewife & $204(21.1)$ & $12(16.5)$ & $192(21.5)$ & \\
\hline Government staff & $160(16.6)$ & $16(21.9)$ & $144(16.1)$ & \\
\hline Artisan/Workers & $130(13.4)$ & $9(12.3)$ & $121(13.5)$ & \\
\hline Pupil / Student & $90(9.3)$ & $10(13.7)$ & $80(8.9)$ & \\
\hline Education & & & & 0.1720 \\
\hline Illiterate/Primary & $450(46.5)$ & $30(41.1)$ & $420(47.0)$ & \\
\hline Secondary school & $296(30.6)$ & $20(27.4)$ & $276(30.9)$ & \\
\hline University & $221(22.9)$ & $23(31.5)$ & $198(22.1)$ & \\
\hline Marital status & & & & 0.1487 \\
\hline Married & $740(76.5)$ & $51(69.9)$ & $689(77.1)$ & \\
\hline Widowed & $124(12.8)$ & $7(9.6)$ & $117(13.1)$ & \\
\hline Single & $103(10.7)$ & $15(20.5)$ & $88(9.8)$ & \\
\hline Total & 967 & 73 & 894 & \\
\hline
\end{tabular}

GDM: Gestational diabetes mellitus

Table 2. Distribution of pregnant "GDM Case" and "Controls" women by obstetric history at university hospital of Porto-Novo, Benin, 2015-2017

\begin{tabular}{|c|c|c|c|c|}
\hline Variables & Total n (\%) & GDM cases n (\%) & Controls n (\%) & $\mathbf{p}$ \\
\hline Number of pregnancies & & & & 0.2123 \\
\hline 1 & $147(15.2)$ & $6(8.2)$ & $141(15.8)$ & \\
\hline $2-3$ & $474(49.0)$ & $37(50.7)$ & $437(48.9)$ & \\
\hline 4 and over & $346(35.8)$ & $30(41.1)$ & $316(35.3)$ & \\
\hline Number of delivery & & & & 0.1099 \\
\hline 0 & $174(17.9)$ & $8(10.9)$ & $166(18.6)$ & \\
\hline 1 & $253(26.2)$ & $17(23.3)$ & $236(26.4)$ & \\
\hline $2-3$ & $399(41.3)$ & $37(50.7)$ & $362(40.5)$ & \\
\hline 4 and over & $141(14.6)$ & $11(15.1)$ & $130(14.5)$ & \\
\hline \multicolumn{5}{|l|}{ Other obstetric history } \\
\hline Stillbirths & & & & $0.18 \times 10^{-4}$ \\
\hline Yes & $158(16.3)$ & $25(34.2)$ & $133(14.9)$ & \\
\hline No & 809 (83.7) & $48(65.8)$ & $761(85.1)$ & \\
\hline \multicolumn{2}{|l|}{ Spontaneous miscarriages $(>2)$} & & & 0.0069 \\
\hline Yes & $301(31.1)$ & $33(45.2)$ & $268(30.0)$ & \\
\hline No & $666(68.9)$ & $40(54.8)$ & $626(70.0)$ & \\
\hline Fetal macrosomia & & & & $0.13 \times 10^{-5}$ \\
\hline Yes & $26(2.7)$ & $9(12.3)$ & $17(1.9)$ & \\
\hline No & $94197.3)$ & $64(87.7)$ & $877(98.1)$ & \\
\hline Total & 967 & 73 & 894 & \\
\hline
\end{tabular}

GDM: Gestational diabetes mellitus 
Table 3. Distribution of GDM cases and controls by family history and individual medical history at university hospital of Porto-Novo, Benin, 2015-2017

\begin{tabular}{|c|c|c|c|c|}
\hline Variables & Total n (\%) & GDM Cases n (\%) & Controls n (\%) & $\mathbf{p}$ \\
\hline \multicolumn{5}{|c|}{ Individual medical history } \\
\hline High blood pressure & & & & 0.0024 \\
\hline Yes & $26(2.7)$ & $6(8.2)$ & $20(2.2)$ & \\
\hline No & $941(97.3)$ & $67(91.8)$ & $874(97.8)$ & \\
\hline BMI & & & & 0.0000 \\
\hline$[18.5-25[$ & $614(63.5)$ & $13(17.8)$ & $601(67.2)$ & \\
\hline$[25-30[$ & $220(22.7)$ & $19(26.0)$ & $201(22.5)$ & \\
\hline 30 and over & $133(13.8)$ & $41(56.2)$ & $92(10.3)$ & \\
\hline \multicolumn{5}{|l|}{ Family medical history } \\
\hline First-degree diabetes & & & & 0.0005 \\
\hline Yes & $98(10.1)$ & $16(21.9)$ & $82(9.2)$ & \\
\hline No & $869(89.9)$ & $57(78.1)$ & $812(90.8)$ & \\
\hline High blood pressure & & & & 0.1079 \\
\hline Yes & $73(7.5)$ & $9(12.3)$ & $64(7.2)$ & \\
\hline No & $894(92.5)$ & $64(87.7)$ & $830(92.8)$ & \\
\hline Total & 967 & 73 & 894 & \\
\hline
\end{tabular}

GDM: Gestational diabetes mellitus

BMI: Body mass index

Table 4. Risk factors for gestational diabetes mellitus at university hospital of Porto-Novo, Benin, 2015-2017

\begin{tabular}{|c|c|c|c|c|c|}
\hline Risk factors & GDM Cases & Controls & OR & CI 95\% & p \\
\hline Maternal age $\geq 35$ years & $42 / 73$ & $132 / 894$ & 7.82 & $4.75-12.89$ & $\mathbf{0 . 0 0 0 0}$ \\
\hline Body mass index $\geq 25 \mathrm{~kg} / \mathrm{m}^{2}$ & $60 / 73$ & $291 / 894$ & 9.56 & $5.17-17.70$ & $\mathbf{0 . 0 0 0 0}$ \\
\hline First degree family diabetes & $16 / 73$ & $82 / 894$ & 2.78 & $1.53-5.06$ & $\mathbf{0 . 0 0 0 5}$ \\
\hline Individual high blood pressure & $6 / 73$ & $20 / 894$ & 3.91 & $1.52-10.07$ & $\mathbf{0 . 0 0 2 4}$ \\
\hline Antecedent of fetal macrosomia & $9 / 73$ & $17 / 894$ & 7.25 & $3.11-16.92$ & $\mathbf{0 . 1 3} \times \mathbf{1 0}^{-5}$ \\
\hline Antecedent of stillbirth & $25 / 73$ & $133 / 894$ & 2.98 & $1.78-5.00$ & $\mathbf{0 . 1 8} \mathbf{x} \mathbf{1 0}^{-4}$ \\
\hline Antecedent of spontaneous miscarriages $(>2)$ & $33 / 73$ & $268 / 894$ & 1.93 & $1.19-3.12$ & $\mathbf{0 . 0 0 6 9}$ \\
\hline
\end{tabular}

GDM: Gestational diabetes mellitus

OR: Odds Ratio, CI 95\%

CI: Confidence interval

\section{Discussion}

\subsection{Prevalence of Gestational Diabetes Mellitus}

Gestational diabetes mellitus was a frequent condition in antenatal cares attendees at the University Hospital Center of Porto-Novo with a prevalence of $7.5 \%$. According to the other studies carried out in Cotonou in southern Benin, the prevalence of gestational diabetes has doubled in less than 30 years: $3.2 \%$ in 1988 [12], $4.4 \%$ in 1998 [13] and $6.5 \%$ in 2013 [14]. Globally, the prevalence of gestational diabetes mellitus in the world varies between 3 and 15\% [14-17] with disparities from one continent to another. In Africa, a few studies have reported a prevalence of gestational diabetes varying from 5 to $17 \%$ [18-20]. In the United States, this prevalence doubled from $1.5 \%$ in $1989-1990$ to $4.2 \%$ in 2001-2004 [21]. In France, the prevalence of gestational diabetes varies from 2 to $6 \%[22,23]$.

Once considered a rare disease in Africa, the incidence of diabetes and particularly of gestational diabetes mellitus is growing in African countries [18-20]. The increasing prevalence in developing countries is related to decreasing levels of physical activity, changes in dietary patterns (transitional nutrition) and increasing rate of obesity [24].

\subsection{Risk Factors of Gestational Diabetes Mellitus}

Several strategies for the detection of GDM are proposed to be done most often between 24 and 28 weeks of amenorrhea. Early detection by fasting glucose in the first trimester of pregnancy is recommended if any of the following risk factors are present: mother age $\geq 35$ years, overweight (BMI $\geq 25 \mathrm{~kg} / \mathrm{m}^{2}$ ), first-line family history of type 2 diabetes, personal history of gestational diabetes mellitus or fetal macrosomia $[23,25,26]$. 


\subsubsection{Mother Age}

The average age of pregnant women with GDM in the present report was $33 \pm 4.19$ years compared with $28 \pm 5.66$ years in the control group. The proportion of pregnant women with GDM was significantly higher at a maternal age of 35 years [p <0.05; OR 7.82 CI 95\% (4.75-12.89)]. Maternal age has thus been an important factor in the detection of gestational diabetes as reported in the literature. Indeed, the average age of pregnant women with gestational diabetes is generally between 31 and 35 years [26-27].

\subsubsection{Body Mass Index}

Pregnancy overweight defined by a body mass index $\geq 25$ $\mathrm{kg} / \mathrm{m}^{2}$ is recognized by all authors as a risk factor for gestational diabetes [26-29]. In the present study, overweight was associated with GDM [p $<0.05$; OR 9.56 CI 95\% (5.17-17.70)].

\subsubsection{Family History of $1^{\text {st }}$ Degree Gestational Diabetes Mellitus}

A history of first-degree family diabetes was found in $21.9 \%$ of pregnant with GDM compared with $9.2 \%$ in the control group $(p<0.05)$. There was a relationship between first-degree family diabetes and GDM [OR 2.78 CI 95\% (1.53-5.06)]. Our results were consistent with those reported in scientific literature $[19,29]$.

\subsubsection{Other Risk Factors of Gestational Diabetes Mellitus}

Other risk factors of GDM observed were a personal history of hypertension, histories of more than two spontaneous miscarriages, stillbirth and fetal macrosomia. These factors are reported in the literature as risk factors for GDM and should prompt health care providers to screen early pregnant [23, 29]. Characteristics such as socioeconomic status and multi-deliveries did not appear to be independent risk factors for GDM. This is consistent with the results of the series $(p>0.05)$. In fact, the multiplicity of risk factors and their interactions make the individual risk prediction complex [19-23, 25-29]. Note that the relationship between number or deliveries and GDM is closely related to two potential confounders that are age and body mass index. Indeed, as number of deliveries increases, women being more likely to be elderly and overweight or obese [23, 27, 29].

The limitations of this study are due to the fact that the "Control group" was not matched with the "GDM Cases" for any characteristics. However, the results generated by the study are in agreement with the data from the scientific literature.

\section{Conclusions}

Results showed that maternal age $\geq 35$ years, body mass index $\geq 25 \mathrm{~kg} / \mathrm{m}^{2}$, history of first degree family diabetes, personal history of hypertension, and obstetric history of more than two spontaneous miscarriages, fetal macrosomia and stillbirths were risk factors of GDM. Early detection is desirable for these groups of pregnant women in order to implement timely appropriate therapeutics.

\section{Conflict of Interest}

None

\section{Acknowledgements}

Authors are very grateful to women who participated in the study.

\section{REFERENCES}

[1] Hartling L, Dryden D. M, Guthrie A, Muise M, Vandermeer B, Donovan L. Benefits and harms of treating gestational diabetes mellitus: A systematic review and meta-analysis for the U.S. Preventive Services Task Force and The National Institutes of Health Office of Medical Applications of research. Annals of Internal Medicine 2013; 159(2):123-129.

[2] Hedderson MM, Weiss NS, Sacks DA and al. Pregnancy weight gain and risk of neonatal complications: macrosomia, hypoglycemia and hyperbilirubinemia. Obstet Gynecol. 2006; 108(5):1153-61

[3] HAPO Study Cooperative Research Group. Hyperglycemia and adverse pregnancy outcomes. N Engl J Med. 2008; 358(19):1991-2002.

[4] HAPO Study Cooperative Research Group. Hyperglycemia and adverse pregnancy outcome study: neonatal glycemia. Pediatrics. 2010; 126(6):e1545-52.

[5] HAPO Study Cooperative Research Group. Hyperglycemia and Pregnancy Outcome: preeclampsia. Am J Obstet Gynecol. 2010; 202(3):255.e1-7.

[6] Soheilykhah S, Mogibian M, Saghand S. R, Rashidi M, Piroz $\mathrm{M}$. Incidence of GDM in pregnant women. Iranian $\mathrm{J}$ of Reproductive Medicine 2010; 8(1):24-28.

[7] Rahman A. S, Abbas M. S, Jaffri A, Raza S. R and Sattar F. A. The prevalence of gestational diabetes in patients attending diabetic clinic at Sir Syed Hospital. Pakistan J Pharma 2007; 24(1):37-42.

[8] Hartling L, Dryden D. M, Guthrie A, Muise M, Vandermeer B, Donovan L. Benefits and harms of treating gestational diabetes mellitus: A systematic review and meta-analysis for the U.S. Preventive Services Task Force and The National Institutes of Health Office of Medical Applications of research. Annals of Internal Medicine 2013; 159(2):123-129

[9] Khan R, Ali K, Khan Z. Maternal and fetal outcomes of gestational diabetes mellitus. Goma J Medi Sci 2013;11(1):88-91

[10] Wu Alan. Tielz Clinical Guide to Laboratory Tests. 4th edition 
Philadelphia : Saunders 2006: 1856p

[11] World Health Organization. Diagnostic Criteria and Classification of Hyperglycaemia First Detected in Pregnancy. Geneva 2013:62p

[12] Honliasso AK. Diabète et grossesse : Etude préliminaire à propos de 7 cas recensés dans les maternités de CNHU de Cotonou et du district urbain de Cotonou I. UAC/FSS Cotonou, thèse de médecine $n^{\circ} 88 / 35 ; 1988: 145 p$.

[13] Azandjèmè S. Dépistage du diabète gestationnel au sein d'une population de 321 gestantes de la maternité du CNHU et de la maternité Lagune - Cotonou. UAC/FSS, thèse de médecine $\mathrm{n}^{\circ} 758 ; 1998: 139 \mathrm{p}$.

[14] Dossou E. Contribution à l'étude du diabète gestationnel à Cotonou (Bénin). UAC/FSS, thèse de médecine $\mathrm{n}^{\circ} 176$; 2013:66p.

[15] Landon MB, Nicholson WK. Gestationnel diabetes mellitus. Practice bulletin No 137. American College of Obstetricians and Gynecologists. Obstet Gynecol. 2013; 122 (2 Pt 1): 406-16.

[16] Wang P, Lu MC, Yu CW, Wang LC, Yan YH. Influence of food intake on the predictive value of the gestational diabetes mellitus screening test. American College of Obstetricians and Gynecologists. Obstet Gynecol. 2013; 121 (4):750-8.

[17] Russo LM, Nobles C, Ertel KA, Chasan-Taber L, Whitcomb BW. Physical activity interventions in pregnancy and risk of gestational diabetes mellitus. American College of Obstetricians and Gynecologists. Obstet Gynecol. 2015; 125 (3):576-82.

[18] Metzger BE, Gabbe SG, Persson B and al. Document de synthèse sur le diabète gestationnel au Cameroun. International Association of Diabetes and Pregnancy Study Groups recommendations on the diagnosis and classification of hyperglycemia in pregnancy. Diabetes Care. 2010; 33 (3):676-82.

[19] Ahouiha Motala, Kausshik Ramaiya. Diabète: La pandémie silencieuse et son impact en Afrique subsaharienne. African Changing Diabetes Leadership, Johannesburg. Novo Nordisk. Diabetes Leadership Forum Africa $2010: 1-48$

[20] Bensalem S, Lakehal A, Roula D : Le diabète gestationnel dans la commune de Constantine, Algérie : Etude prospective. Médecine des Maladies Métaboliques. 2014; 8(2):216-220.

[21] Camelo Castillo W, Boggess K, Stürmer T and al. Trends in glyburide compared with insulin use for gestational diabetes treatment in the United States, 2000-2011. American College of Obstetricians and Gynecologists. Obstet Gynecol. 2014; 123(6):1117-84.

[22] Touzet S, Rocher S, Dureau-Drevard E. and al. Etude d'observation des pratiques de dépistage du diabète gestationnel à partir d'une cohorte de 701 femmes. J. Gynecol Obstet Biol Reprod. 2002; 31:248-255.

[23] Collège National des Gynécologues et Obstétriciens Français (CNGOF), Société Francophone du Diabète (SFD): Recommandations pour la pratique Clinique: Le diabète gestationnel. J. Gynecol Obstet Biol Reprod 2010; 39(2-8): S1-S342.

[24] Rajpit R, Yadev Y, Navida S, Rajput M. Prevalence of Gestational diabetes mellitus and associated risk factors at a tertiary care hospital in Haryana. Indian J Med Res 2013; 137(4):728-733.

[25] Mehaoudi RI, Oussekhri H, Soltani Y, Bendaoud H and al. P053 Diagnostic du diabète gestationnel et implication hormonal: impact de l'IMC, de l'âge et des adipokines. Diabetes \& Metabolism. 2015; 41(1):pA46

[26] Jenum AK, Morkid K, Sletner L and al. Impact of ethnicity on gestational diabetes identified with the WHO and the modified International Association of Diabetes and Pregnancy study groups criteria: a population based cohort study. Eur J endocrinal. 2012; 166(2): 317-24

[27] Shin Y. Kim, Andrea J. Sharma, William Sappenfield and al. Association of Maternal Body Mass Index, Excessive Weight Gain, and Gestational Diabetes Mellitus with Large-for-Gestational-Age Births. American College of Obstetricians and Gynecologists. 2014; 123(4): 737-744.

[28] Boulvain M, Brandle M, Drack G. and al. Dépistage du diabète gestationnel. Société Suisse de Gynécologie et d'Obstétrique. Avis d'expert N³7. Juin 2011:p2.

[29] Galtier F. Le diabète gestationnel : Définitions, épidémiologie, facteurs de risque. J. Gynecol Obstet Biol Reprod. 2010; 39(8): S144-S170 